\title{
ON THE PHOTOLUMINESCENCE AND OPTICAL PROPERTIES OF ZINC OXIDE THIN FILMS PREPARED BY THERMAL OXIDATION
}

\author{
DRAGOȘ-IOAN RUSU ${ }^{* 1}$ \\ 1 "Vasile Alecsandri” University of Bacau, Calea Marasesti 157, Bacau, 600115, Romania
}

\begin{abstract}
Zinc oxide $(\mathrm{ZnO})$ thin films were prepared by thermal oxidation of vacuum evaporated metallic zinc films. Some structural investigation, performed by X-ray diffraction technique, showed that films are polycrystalline and have a würtzite structure. We also determined some structural parameters of the films. The optical absorption was studied in the wavelength range from $300 \mathrm{~nm}$ to $1700 \mathrm{~nm}$. Photoluminescence spectra at temperatures $293 \mathrm{~K}$ and $78 \mathrm{~K}$ have been analysed.
\end{abstract}

Keywords: zinc oxide, thin films, structural characteristics, optical properties, photoluminescence spectra

\section{INTRODUCTION}

Zinc oxide $(\mathrm{ZnO})$ is an interesting element of this class which attracted considerable attention owing to various applications such as transparent field-effect transistors, energy-efficient windows, transparent electrodes, flat panel displays, solar cells etc. [1-7]. These applications are based on the optical and electrical characteristics of $\mathrm{ZnO}$ (high transparency in the visible spectral range of the solar spectrum, wide direct energy bandgap, low electrical resistivity at room temperature, high thermal and chemical stability etc.), which are very suitable for a great number of new applications in modern solid state device technologies, transparent electronics, sensor tehnology, optoelectronics etc. [1, 2, 8, 9]. Several different techniques have been successfully employed to prepare transparent conductive $\mathrm{ZnO}$ thin films, such as magnetron sputtering, spray pyrolysis, chemical vapor deposition, sol-gel (spin coating), pulsed laser deposition, molecular beam epitaxy etc. [10].

Some structural and optical [11] properties of zinc oxide thin films prepared by thermal oxidation of zinc metallic films in different conditions were studied.

Some correlations between preparation conditions and structural characteristics of $\mathrm{ZnO}$ thin films have been established.

Due to both theoretical interest and technologic importance, the photoluminescence properties of $\mathrm{ZnO}$ thin films have been intensively studied in the last years $[6,9,10]$.

Zinc oxide is also a potential candidate for the active film in some important modern devices (laser diodes, lightemitting diodes, etc.) due to its large excitonic binding energy (about $60 \mathrm{meV}$ ), which ensures an efficient excitonic emission up to room temperature $[1,6]$.

\footnotetext{
* Corresponding author, email: d_i_rusu@yahoo.com

(c) 2018 Alma Mater Publishing House
} 


\section{EXPERIMENTAL}

Zinc thin films were prepared by thermal evaporation under vacuum onto optically flat borosilicate glass (Corning 7059) and amorphous $\mathrm{SiO}_{2}$ substrates kept at room temperature ( $T=293 \mathrm{~K}$ ) during film deposition.

The thermal oxidation procedure of zinc thin films consisted of following successive technological steps: (1) a heating in open atmosphere (relative humidity was about $60 \%$ ), in the temperature range from $300 \mathrm{~K}$ to $T_{o x}$ (where $T_{o x}$ denotes oxidation temperature), with a temperature rate of about $6 \mathrm{~K} / \mathrm{min}$; (2) an annealing for a certain oxidation time, $t_{o x}\left(t_{o x}=30-120 \mathrm{~min}\right)$ at a determined oxidation temperature $\left(T_{o x}=500-870 \mathrm{~K}\right)$; (3) a cooling from oxidation temperature to room temperature, with a temperature rate of about $10 \mathrm{~K} / \mathrm{min}$. We experimentally established that these preparation conditions permit to obtain $\mathrm{ZnO}$ thin films having a homogeneous structure, stable stoichiometry and very good adhesion to the substrate surface.

The surface morphology of $\mathrm{ZnO}$ thin films was examined by atomic force microscopy (AFM). The scan was carried out in tapping mode.

The reflection and transmission spectra, in vicinity of fundamental absorption band edge \{corrected for the effect of the glass substrate [6]\}, in the spectral range from $300 \mathrm{~nm}$ to $1600 \mathrm{~nm}$ were recorded within temperature range from $78 \mathrm{~K}$ to $293 \mathrm{~K}$ using a Steag ETA Optik computer controlled spectrometer and a Specord UV-VIS-M.40 (C. Zeiss, Jena) spectrophotometer.

The absorption coefficient, $\alpha$, at temperatures $78 \mathrm{~K}$ and $293 \mathrm{~K}$, was calculated from the expression below:

$$
\alpha=\frac{1}{d} \ln \left[\frac{\left[(1-R)^{4}+4+2 R^{2}\right]^{1 / 2}+(1-R)^{2}}{2 T}\right]
$$

where $d$ is the film thickness and $R$ and $T$ are reflection coefficient and transmission coefficient at normal incidence, respectively.

Photoluminescence (PL) was measured perpendicular to the sample surface at room temperature. For studied films the following preparation conditions were used: oxidation temperature, $T_{o x}=750 \mathrm{~K}$; oxidation time was $t_{o x}=60 \mathrm{~min}$; film thickness, $d=140 \mathrm{~nm}$. The excitation of photoluminescence was performed by using as excitation source the monochromatic radiation $(\lambda=337.4 \mathrm{~nm})$ from $\mathrm{N}_{2}$ laser emitting pulses at a frequency up to $82 \mathrm{~Hz}$. The incident beam, with a density up to $100-500 \mathrm{~W} / \mathrm{cm}^{2}$ can be attenuated by using a set of calibrated filters.

The PL spectra at temperature $78 \mathrm{~K}$ were recorded by a MDR-2 monochromator with a diffraction grating (1200 $\mathrm{mm}^{-1}$ ) and as detector a photomultiplier has been used.

\section{RESULTS AND DISCUSSION}

\subsection{Microstructural characteristics}

For $\mathrm{ZnO}$ thin films studied in present paper the following values of main preparation parameters were used: zinc films were deposited by vacuum thermal evaporation, onto glass substrates (the deposition conditions were previously indicated); oxidation temperature was $T_{o x}=700 \mathrm{~K}$; oxidation time, $t_{o x}=30 \mathrm{~min}$; the thickness of $\mathrm{ZnO}$ films was about $270 \mathrm{~nm}$.

Typical XRD patterns are presented in Figure 1 for unoxidized zinc film (with thickness $d=190 \mathrm{~nm}$ ) prepared by described method.

Different peaks were indexed and the values of the interplanar spacing, $d_{h k l}$, were determined and compared with a standard values for $\mathrm{ZnO}$ polycrystalline powder.

The XRD pattern of Zn metallic films indicates a poor crystallization of the films. Some structural characteristics of one $\mathrm{ZnO}$ thin film are presented in Table 1. 


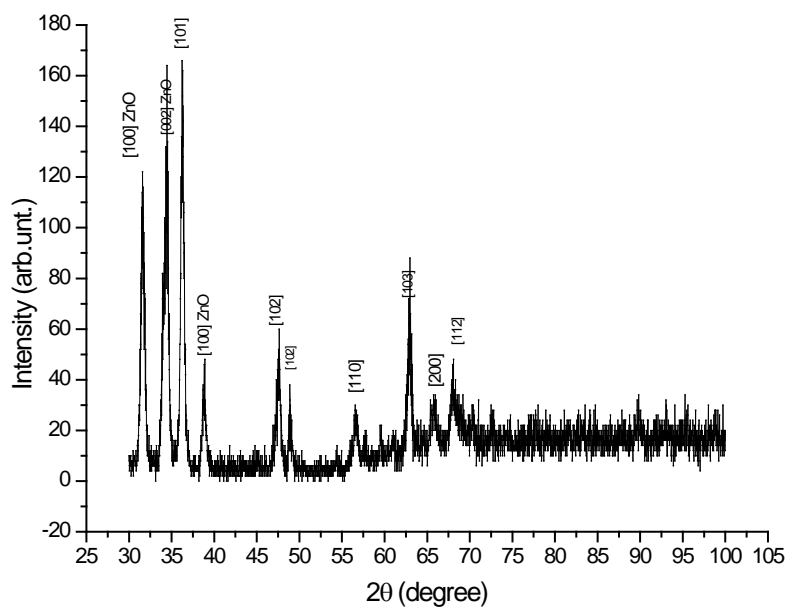

Fig. 1. Typical XRD pattern for ZnO thin film.

Table 1. Values of structural parameters of the investigated $\mathrm{ZnO}$ thin films.

\begin{tabular}{|c|c|c|c|c|c|c|c|}
\hline \multirow{2}{*}{ Sample } & $\begin{array}{c}2 \theta \\
\text { [degree] }\end{array}$ & $(\mathrm{hkl})$ & $\begin{array}{c}d_{h k l} \\
(\AA)\end{array}$ & $\begin{array}{c}D \\
(\AA)\end{array}$ & $\begin{array}{c}a \\
(\AA)\end{array}$ & $\begin{array}{c}c \\
(\AA)\end{array}$ & $\begin{array}{c}L \\
(\AA)\end{array}$ \\
\hline \multirow{3}{*}{ ZNO.042 } & 31.72 & $(100)$ & 2.819 & 165 & 3.259 & - & 1.913 \\
\cline { 2 - 8 } & 34.38 & $(002)$ & 2.606 & 145 & - & 5.213 & 1.913 \\
\cline { 2 - 8 } & 36.20 & $(101)$ & 2.482 & 185 & - & - & - \\
\hline
\end{tabular}

$\theta$ - Bragg angle; ( $h k l)$ - Miller indices; $d_{h k l}$ - interplanar spacing of (hkl) planes; $D$-crystallite size; $a, c$ - lattice parameters of the hexagonal (würtzite) structure; $L$ - the $\mathrm{Zn}-\mathrm{O}$ bond length.

The obtained values of $a$ and $c$ are in agreement with those of ZnO, given in JCPDS data cards (standard values for polycrystalline powder are: $a=3.249 \AA, c=5.206 \AA$ ).

The average crystallite size, $D$, can be estimated by means of Debye-Scherrer expression [12-14]:

$$
D=\frac{k \lambda}{\beta_{2 \theta} \cos \theta}
$$

where: $k$ denotes the Scherrer's constant, $\lambda$ is the wavelength of $\mathrm{CuK}_{\alpha}$ radiation $(\lambda=1.5418 \AA), \theta$ is Bragg diffraction angle and $\beta_{2 \theta}$ represents the full width at half maximum intensity of the diffraction peak located at angle $\theta$.

All films show the most preferred orientation (002) planes parallel to substrate. The preferred degree orientation decreases with increasing film thickness.

For studied samples, the average crystallite size, determined from Debye-Scherrer formula, ranged between $14.5 \mathrm{~nm}$ and $18.5 \mathrm{~nm}$ and are higher for films with greater thickness.

The Zn-O bond length, $L$, can be determined from the expression [12-14]:

$$
L=\left[\frac{a^{2}}{3}+\left(\frac{1}{2}-u\right)^{2} c^{2}\right]
$$


where würtzite structure parameter, $u$, is given by:

$$
u=\frac{a^{2}}{3 c^{2}}+0.25
$$

where $a$ and $c$ are lattice parameters.

The relatively small values (for $\mathrm{ZnO}$ single crystals, $L=2.21 \AA$ ) for our samples indicate the presence of structural defects (especially oxygen vacancies).

\subsection{Optical properties}

\subsubsection{Absorption coefficient}

The films used for the study of the absorption coefficient have been prepared by following technology: zinc films were deposited onto amorphous $\mathrm{SiO}_{2}$ substrates; oxidation temperature, $T_{o x}=835 \mathrm{~K}$; oxidation time, $t_{o x}=$ $110 \mathrm{~min}$.

For the study of the optical characteristics of $\mathrm{ZnO}$ thin films, the heat treated samples were used.

The transmission coefficient lies in the range $70 \%-80 \%$ in the visible domain. This high transmission coefficient is due to relatively small roughness of the film surface.

The typical absorption spectra for a $\mathrm{ZnO}$ thin film is presented in Figure 2. The dependences $\alpha=\mathrm{f}(h v)$ at temperature $293 \mathrm{~K}$ consists of an absorption band $\left(\alpha_{\max }=5.8 \times 10^{5} \mathrm{~cm}^{-1}\right)$ with maximum at $3.343 \mathrm{eV}$.

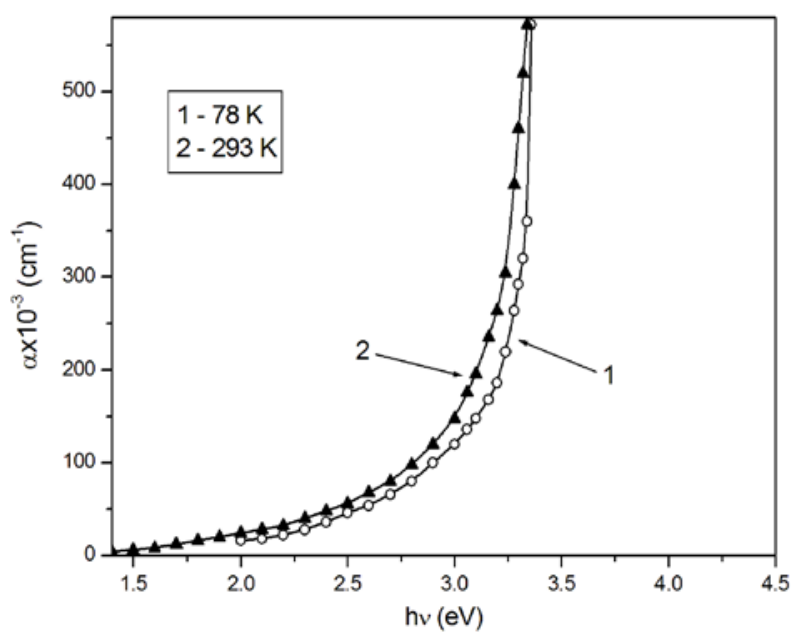

Fig. 2. Typical absorption spectra for a $\mathrm{ZnO}$ thin film.

For a studied $\mathrm{ZnO}$ thin film, absorption spectra at temperatures $293 \mathrm{~K}$ and $78 \mathrm{~K}$ are presented in Figure 3. By analyzing these absorption spectra at different temperatures, one can state that the edge of intrinsic absorption band of studied $\mathrm{ZnO}$ thin film is located in the energy range from $3.4 \mathrm{eV}$ to $3.5 \mathrm{eV}$.

The studied $\mathrm{ZnO}$ thin films have a high transmission coefficient in visible spectral range (300 nm - $1650 \mathrm{~nm}$ ).

The Urbach's rule must be inserted [as Eq. (5)], together with some comments. For studied sample, $\sigma_{0}=3.20 \times 10^{-3}$ at $293 \mathrm{~K}$ and $\sigma_{0}=15.5 \times 10^{-3}$ at $78 \mathrm{~K}$ while $E_{u}=4.86 \mathrm{eV}$ at $293 \mathrm{~K}$ and $E_{u}=0.434 \mathrm{eV}$ at $78 \mathrm{~K}$. The obtained values show that width of the band tail is greater at low temperature. $\sigma_{0}$ is called the steepness parameter which characterizes the absorption edge shape determined by electron-phonon or/and exciton-phonon interactions. 


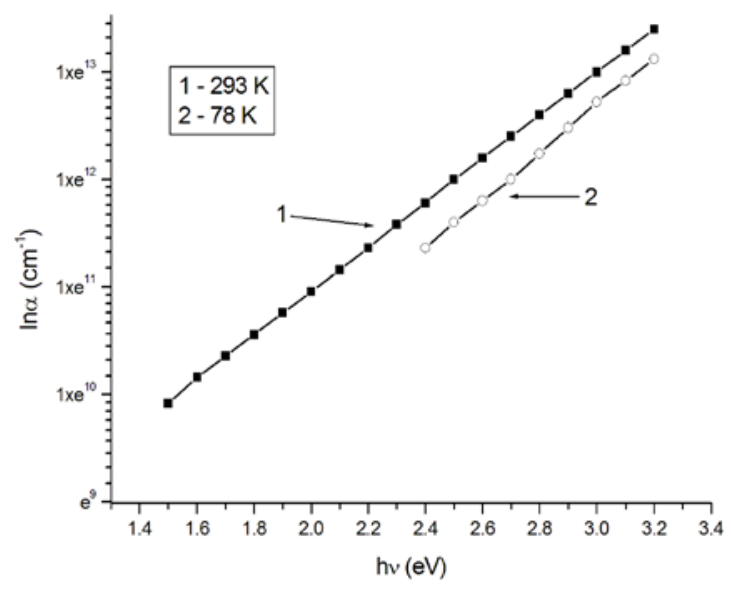

Fig. 3. Absorption spectra for studied ZnO thin film.

\subsubsection{Photoluminescence spectra}

The following preparation conditions were used for oxidation of $\mathrm{Zn}$ metallic films: oxidation temperature, $T_{o x}=700 \mathrm{~K}$, oxidation time, $t_{o x}=90 \mathrm{~min}$. The zinc films were deposited onto $\mathrm{SiO}_{2}$ substrates at room temperature by employing a technology described above. The film thickness was $d=270 \mathrm{~nm}$.

The typical photoluminescence spectra at temperatures $T=293 \mathrm{~K}$ and $78 \mathrm{~K}$ are shown in Figure 4.

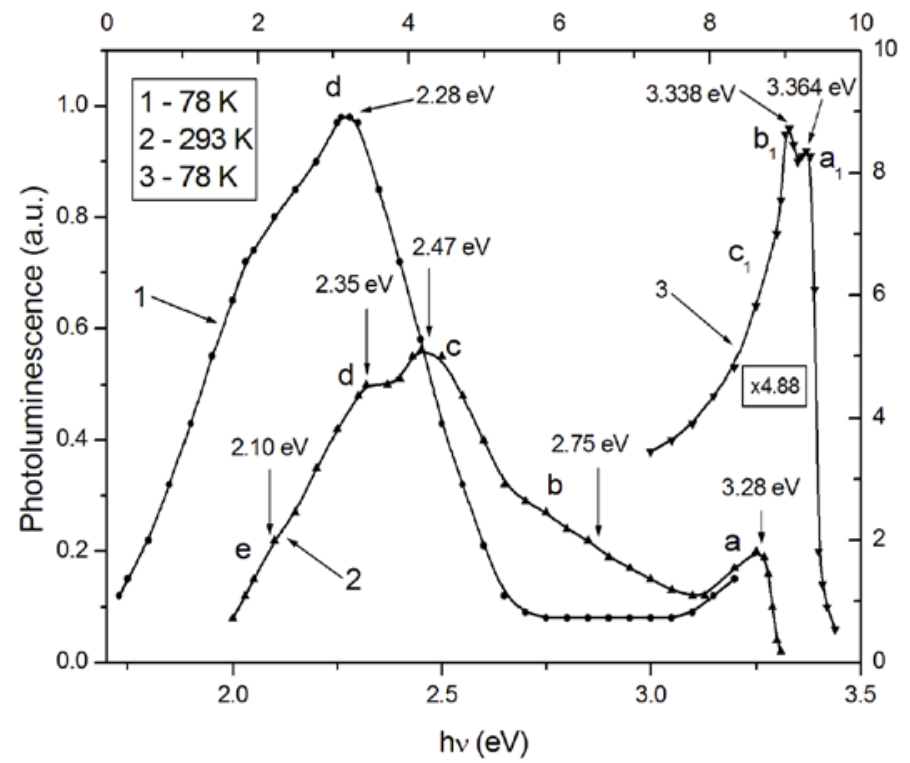

Fig. 4. The typical photoluminescence spectra for a $\mathrm{ZnO}$ thin film.

At temperature of $293 \mathrm{~K}$, the spectral dependences of photoluminescence (curve 2) relieve the edge band with a clear maximum at $3.28 \mathrm{eV}$ (a) and a complex band with four sub-bands having an absolute broad maximum at $2.47 \mathrm{eV}(\mathrm{c})$.

This emission bands at $500 \mathrm{~nm}$ are determined to the energy level of oxygen vacancies in the energy bandgap.

The luminescence band in visible spectral range consists of four sub-bands (indicated by a, b, c and d): two subbands are located in green range of spectrum at $2.47 \mathrm{eV}$ (c) and $2.35 \mathrm{eV}$ (d), one subband in blue range with a 
weak maximum at $2.75 \mathrm{eV}$ and another subband in the orange range of spectrum which has a maximum at 2.10 $\mathrm{eV}$.

As it can be observed by comparison with the absorption spectra and photoluminescence spectra, the (a) band is shifted to smaller energies by $60 \mathrm{meV}$. This value is in good agreement with Zn-O phonon energy in studied oxide. It can be supposed that band (a) of photoluminescence is obtained as the radiative emission of excitonic transitions with the phonon emission with energy of about $60 \mathrm{meV}$.

The dominant band in PL spectra which has a maximum at $2.47 \mathrm{eV}$ is explained as the recombination of holes from valence band with electrons from singly ionized level of oxygen vacancies.

The band (b) is considered as the luminescent recombination of an electron from a small-energy-donor-level with a hole from valence band. The (e) band in the orange range is the result of recombination of nonequilibrium electrons from conduction band through ionized oxygen vacancies.

At the temperature of $78 \mathrm{~K}$ (curve 1) the structure of two bands is the same in PL spectra. The dominant band from yellow range of spectrum has an impurity nature with the maximum at $2.280 \mathrm{eV}(\mathrm{d})$. Beside, at this temperature, the recombination band of electrons from the conduction band with double ionized oxygen vacancies $(h v=2.10 \mathrm{eV})$ is present. The edge band at temperature $T=78 \mathrm{~K}$ could be decomposed into two subbands with maximums at $3.364 \mathrm{eV}\left(\mathrm{a}_{1}\right)$ and $3.338 \mathrm{eV}\left(\mathrm{b}_{1}\right)$, and a plateau at $3.280 \mathrm{eV}\left(\mathrm{c}_{1}\right)$. The PL band with maximum at $3.338 \mathrm{eV}$ is the result of annihilation of free excitons (state $n=1$ ) with the emission of optical phonons, because the phonons energy in $\mathrm{ZnO}$ films is equal to about $56 \mathrm{meV}$. The threshold at $3.280 \mathrm{eV}$ can be associated to luminescence of donor-acceptor pair recombination. These peaks can be interpreted as an excitonic transition of bound excitons to neutral donors.

As it can be seen, at temperature of $78 \mathrm{~K}$ the PL spectrum is dominated by a strong near-band-edge peak which is positioned at $3.27 \mathrm{eV}$. This main peak may be attributed to the free-to-bound excitonic emission as peak positions did not change with energy values of excitation source.

There is a smaller peak at about $1.308 \mathrm{eV}$ which is due to structural defects.

It was established that the position of this last peak did not change with the wavelength of the exciting photons.

\section{CONCLUSIONS}

Zinc thin films were prepared by thermal evaporation under vacuum onto optically flat borosilicate glass substrates kept at room temperature $(T=293 \mathrm{~K})$ during film deposition.

The structural investigations show that the phase composition of $\mathrm{ZnO}$ films is not influenced by film thickness and used oxidation conditions.

The intrinsic absorption band of $\mathrm{ZnO}$ films is formed by free excitons. The width of band gap at the temperature of $78 \mathrm{~K}$ of $\mathrm{ZnO}$ films is $3.459 \mathrm{eV}$. The binding energy of electron-gap bound is $67 \mathrm{meV}$.

The $\mathrm{ZnO}$ films show intense photoluminescence in the UV and visible range. The high energy edge of PL spectrum is determined by the luminescence caused by annihilation of excitons from state $n=1$ bounded to ionized centers.

\section{REFERENCES}

[1] Hartnagel, H.L., Dawar, A.L., Jain, A.K., Jagadish, C., semiconducting transparent thin films, Institute of Physics Publishing, Bristol and Philadelphia 1995.

[2] Harbeke, G., Polycristallyne Semiconductors: Physical properties and applications, Springer Verlag, Berlin 1985.

[3] Lee, J.B., Cho, D.H., Kim, D.Y., Park, C.K., Park, J.S., Thin solid films, vol. 516, 2007, p. 475-480.

[4] Tsuda, N., Nasu, K., Fujimori, A., Siratori, K., Electronic conduction in oxides, Springer, Berlin-Heidelberg, 2000. 
[5] El Amrani, A., Hijazi, F., Lucas, B., Boucle, J., Aldissi, M., Thin solid films, vol. 518, 2010, p. $4582-4585$.

[6] kazmerski, l.l., polycrystalline and amorphous Thin Films and Devices, Academic Press, New York, 1980.

[7] Chang, J.F., Kuo, H.H., Leu, I.C., Hon, M.H., Sensor actuators, B: Chemical, vol. B4, 2002, p.258.

[8] Forrest, S.R., 4.2\% efficient organic photovoltaic cells with low series resistances, Applied Physics Letters, vol. 84, 2004, p. 3013.

[9] Lee, C.Y., Hui, Y.Y., Su, W.F., Liu, C.F., Electroluminescence from monolayer ZnO nanoparticles using dry coating technique, Applied Physics Letters, vol. 92, 2008, p. 261107.

[10] Suchea, M., Christoulakis, S., Katsarakis, N., Kitsopoulas, T., Kiriakidis, G., ZnO transparent thin films for gas sensor applications, Thin Solid Films, vol. 515, 2007, p. 551-554.

[11] Moșneguțu, E., Nedeff, V., Panainte-Lehăduș, M., Bârsan, N, Chițimuş, D., Rusu, D., Determination of the real values of kinematic index corresponding to the mechanical separation process, Journal of Engineering Studies and Research, vol. 22, no. 2, 2016, p. 39-48.

[12] Rusu, G.G., Gartan, M., Rusu, M., Preparation and characterization of ZnO thin films prepared by thermal oxidation of evaporated Zn thin films, Superlattices Microstructures, vol. 42, 2007, p. 116-122.

[13] Rambu, A.P., Sirbu, D., Rusu, G.I., Influence of the oxidation conditions on the structural characteristics and optical properties of zinc oxide thin films, Journal of Vacuum Science Technology, vol. 28, 2010, p. 1344

[14] Rusu, D.I., Rusu, G.G., Luca, D., Structural characteristics and optical properties of thermally oxidized zinc films, Acta Physica Polonica A, vol. 119, no. 6, 2011, p. 850-856. 